\title{
Serviceability of Reinforced Concrete Gable Roof Beams with Openings under Static Loads
}

\author{
Maryam Abdul Jabbar Hassan \\ College of Engineering, Department of Civil Engineering, \\ University of Baghdad, Baghdad, Iraq \\ maryemaj123@gmail.com
}

\author{
Amer Farouk Izzet \\ College of Engineering, Department of Civil Engineering, \\ University of Baghdad, Baghdad, Iraq \\ amer.f@coeng.uobaghdad.edu.iq
}

\begin{abstract}
This paper presents an analytical study on the serviceability of reinforced concrete gable roof beams with openings of different sizes, based on an experimental study which includes 13 concrete gable roof beams with openings under static loading. For deflection and crack widths under static loading at service stage, a developed unified calculation procedure has been submitted, which includes prismatic beams with one opening subjected to flexure concentrated force. The deflection has been calculated with two methods: the first method calculated deflections via relevant equations and the second was Direct Stiffness Method in which the beam is treated as a structural member with several segments constituting the portions with solid sections and those with sections crossed by the opening. The crack width was calculated with the ACI code's equation with a proposed magnification factor equal to 1.125 . The analytical results were compared with the experimental ones and a good agreement was obtained.
\end{abstract}

Keywords-serviceability; gable roof beam; deflection; crack width; static loads

\section{INTRODUCTION}

Concrete has relatively low material costs, good high fire resistance, and low to no maintenance cost. For these reasons reinforced concrete gable beams can be used as an alternative preferred option to support roofs of warehouses, industrial buildings, and airplane hangars. The presence of openings in gable beams has many advantages, such as easier handling or overall weight reduction, but the insertion openings in a solid beam would directly affect beam behavior as the opening would essentially cause a sudden drop in the beam cross section dimensions which would in turn reduce the overall stiffness of the beam which may result in extreme deflections under service loads. Gable beams are non-prismatic beams or beams of variable cross-section which make the calculation of the moment of inertia more complicated [1]. The presence of openings would lead to further complication. To the best of our knowledge, there is no literature regarding the deflection of reinforced concrete gable roof beams with openings. Therefore, this research is an attempt to present an analytical study of the deflection for RC gable roof beams with openings based on previous studies of prismatic beams with one opening.

Authors in [2] presented a simple method to evaluate the deflection at service stage of simply supported beams with openings. The upper and lower chords of opening behave as struts framing on sides of the opening into rigid abutments. The effective length le is equal to the distance between full-depth stirrups on the sides of opening. The point of contra flexure is assumed at mid-length of each strut, so that each half of upper and lower chords bends as a cantilever. Authors in [3] proposed a rigorous method to calculate the deflection of beams with openings. In this methodology, the beam is treated as a structural member with several segments constituting the portions with solid sections and those with sections crossed by the opening. An equivalent stiffness is adopted for the latter segments and the beam can be analyzed using methods such as the Direct Stiffness Method. Both previous methods have been used to calculate the deflection of prismatic beams with only one rectangular opening. In the present study an attempt was made to develop these methods to calculate deflection for gable beams with openings of different sizes.

Crack width is one of the major serviceability requirements of concrete structures, concrete's low tensile strength leads to crack occurrence in reinforced concrete under service loads. Cracking control is essential for the acceptable appearance and durability of concrete structures, particularly those subjected to aggressive environment [4]. The ACI 318M-1995 code [5], considered that the permissible maximum crack widths at service stages for exterior and interior exposure conditions are $0.3 \mathrm{~mm}$ and $0.4 \mathrm{~mm}$, respectively. Authors in [6] examined the influence of circular openings on the structural behavior of concrete beams. The adopted parameters were: the opening diameter, the location of the opening, the reinforcement type and place, and the concrete compressive strength. The main findings were that the ultimate strength reduction and the pattern of cracking were magnified in normal concrete beams, when the opening diameter exceeded the one-third of the beam's depth. The diameter and the opening location are the main parameters that affect the strength of concrete. It is preferable to use inclined bar reinforcement around the opening, to control the cracks and restrict their width. Using inclined bar reinforcement and stirrups in the upper and lower chords of the opening is necessary to increase the ultimate shear strength. For beams with openings, wide cracks appear close to the end of chord members at the opening corner due to stress concentration at these zones [7-11]. 


\section{DEFLECTION AT SERVICE LOAD}

\section{A. Equation Method}

Maximum deflection under working loads is generally required to be in agreement with code provisions. In the present analysis, service load is taken as the experimental ultimate load divided by a factor of 1.7 as recommended by [3, 12]. A simple method to estimate the mid-span deflection of simplysupported beams with openings is suggested in [2]. The maximum deflection of the beam can be calculated as:

$$
\delta=\delta_{w}+\left(\delta_{v}\right)_{\text {opening } 1}+\left(\delta_{v}\right)_{\text {opening } 2}+\cdots
$$

where $\delta_{w}$ is the mid-span deflection of the beam in the absence of openings and $\delta_{v}$ is the relative displacement of one end of the opening with respect to the other end under the action of $V$, which may be obtained as:

$$
\delta_{v}=\frac{V l_{e}^{3}}{12 E_{c}\left(I_{t}+I_{b}\right)}
$$

where $E_{c}$ is the modulus of elasticity of concrete. Under service load, $I_{t}$ is the moment of inertia of the upper chord which may be based on gross concrete section, while $I_{b}$ is the moment of inertia of the lower chord which can be conservatively based on a fully cracked section. The effective length $l_{e}$ of the struts is conservatively taken as the distance between the full-depth stirrups on each side of the opening (as mentioned previously).

In the present study an attempt has been drawn to calculate the deflection of the tested beams under service loads applying the above equations as follows:

$P_{s}=$ assumed service load $=P_{u} / 1.7, V=$ corresponding shear force $=P_{s} / 2, L_{e}=$ the effective length of opening $=l_{\text {opening }}+50 \mathrm{~mm}$, $E_{c}=$ modulus of elasticity of concrete from testing $=26870 \mathrm{MPa}$, $I_{i}=$ the moment of inertia of the upper chord $=\frac{b * h^{3}}{12}, I_{b}=$ the moment of inertia of the lower chord $=0.1 I_{t}$, and $\delta_{w}=$ the midspan deflection of the beam with span $L=P L^{3} / 48 E_{c} I$, where $I$ can be conservatively estimated as the moment of inertia of the beam.

Authors in [13] suggested a prismatic beam with one rectangular opening in which $I$ can be calculated at a section through the opening based on gross concrete section. While this suggestion contradicts the definition of $\delta_{w}$ in (1) (mid-span deflection in the absence of openings), the service stage deals with cracked transformed sections, so that using gross section gives high values of $I$ which in turn leads to a very small value of deflection which is far from the real value. For above reasons, it may be suggested that $I$ for service load can be calculated based on the cracked transformed section for the beam in the absence of openings. To calculate $I$ for a nonprismatic beam, the section that reflects the uniform change in dimension (height) with length must be determined. After several trials it was found that the cracked transformed section at the quarter length of the gable beam can be used to calculate $I_{\text {average }}$ and converge to the experimental results of the gable beam without openings. The height at any distance $\left(h_{x}\right)$ can be calculated from the following equation (Figure 1):

$$
h_{x}=h_{o}\left(1-\frac{x}{L_{1}}\right)+\frac{x}{L_{1}} h_{1}
$$

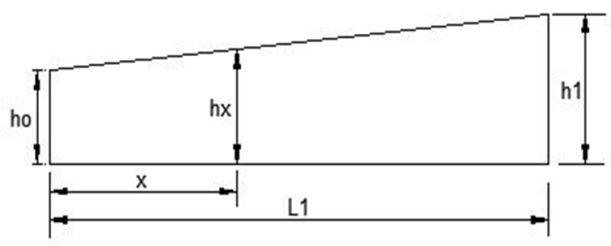

Fig. 1. Schematic layout of a gable beam

\section{B. Direct Stiffness Method}

Another way to calculate maximum beam deflections beside the deflections under each opening corner at the assumed service loads is the one where the beam is treated as a structural member with several segments constituting the portions with solid sections and those with sections crossed by the openings. An equivalent stiffness is adopted for the latter segments and the beam can be analyzed using methods such as the Direct Stiffness Method [3]. The equivalent flexural stiffness $(E I)_{e q}$ of the continuous medium is based on the net section through the opening, assuming that the two chords act as one unit and that the section is cracked in flexure, the moment of inertia $I$ is calculated using the transformed area method (Figure 2).
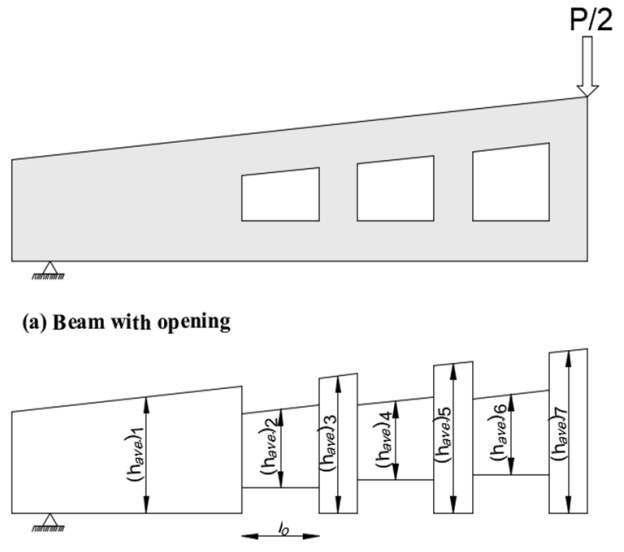

(b) Equivalent beam

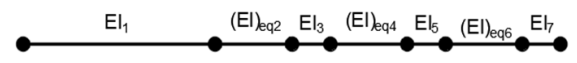

(c) Equivalent restrained structure

Fig. 2. Equivalent segmented beam

The beam is divided into sections of different crosssectional properties: the solid section and the equivalent opening section as shown in Figure 2(b), and the flexural stiffness is based on the cracked transformed section. The case of analyzing a simply supported beam with symmetrical multiple openings can be deduced due to this symmetry as shown in Figure 2. The typical equation used in the analysis is:

$$
\{F\}=[K]\{\delta\}
$$


where the stiffness matrix $[\mathrm{K}]$ for any element with length $L$ is:

$$
[K]=\left[\begin{array}{cccc}
\frac{12}{L^{3}} & \frac{6}{L^{2}} & -\frac{12}{L^{3}} & \frac{6}{L^{2}} \\
\frac{6}{L^{2}} & \frac{4}{L} & -\frac{6}{L^{2}} & \frac{2}{L} \\
-\frac{12}{L^{3}} & -\frac{6}{L^{2}} & \frac{12}{L^{3}} & -\frac{6}{L^{2}} \\
\frac{6}{L^{2}} & \frac{2}{L} & -\frac{6}{L^{2}} & \frac{4}{L}
\end{array}\right]
$$

III. COMPARISON WITH TEST DATA (SUMMARY OF BEAM DETAILS)

The experimental data were acquired from the testing of 13 reinforced concrete gable roof beams, including the reference beam without openings (solid) and 12 beams with openings. The variables used in this work include the size and number of the openings, the inclination of the posts, and the configuration of the openings, as shown in Table I. All beams had the same length, width, height, reinforcement details, and were subjected to one mid-point concentrated load. Precautions were made to avoid local failure at the loading point and support was provided by steel plates. Figures 3 to 7 show the details of the tested beams. The beams were tested with an overall clear span of $2800 \mathrm{~mm}$. The tested beams were divided into four main groups (A, B, C, and D). These groups were classified according to the variables that have been used in this study (Table I)

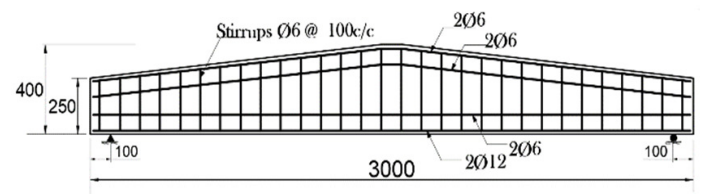

Fig. 3. Details of reinforcement for beam GB (all dimensions are in $\mathrm{mm}$ )

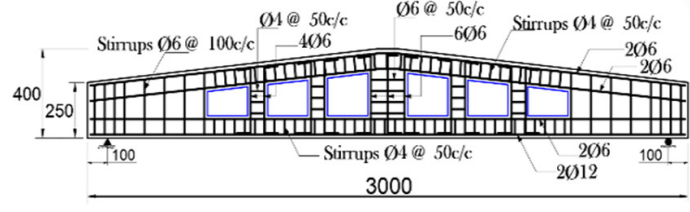

Fig. 4. Details of reinforcement for beam GT6

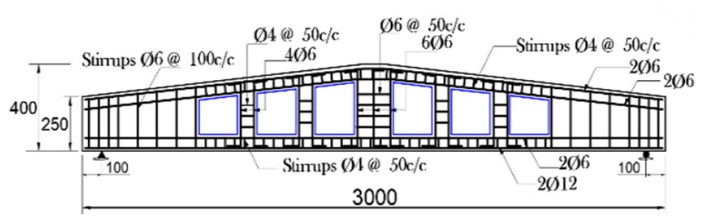

Fig. 5. Details of reinforcement for beam GTH6

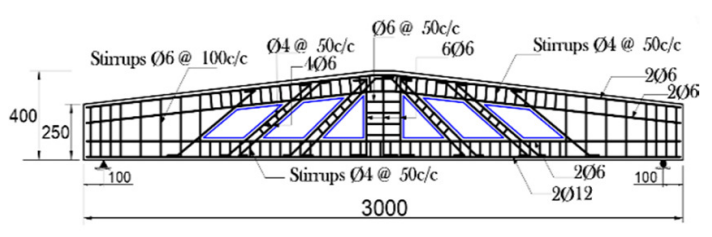

Fig. 6. Details of reinforcement for beam GP6

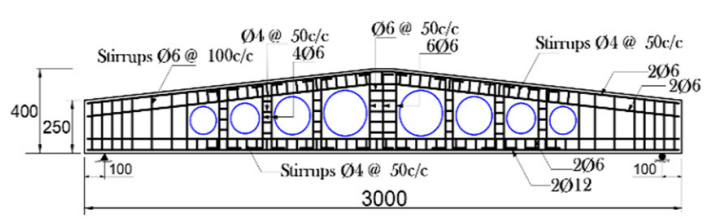

Fig. 7. Details of reinforcement for beam $\mathrm{GC1}$

TABLE I. DETAILS OF TESTED BEAMS

\begin{tabular}{|c|c|c|c|c|c|c|}
\hline Group & Beam Mark & Shape of openings & $\begin{array}{c}\text { Number of } \\
\text { openings }\end{array}$ & $\begin{array}{c}\text { Width of openings } \\
(\mathrm{mm})\end{array}$ & $\begin{array}{l}\text { Height of upper } \\
\text { chord (mm) }\end{array}$ & $\begin{array}{l}\text { Height of lower } \\
\text { chord (mm) }\end{array}$ \\
\hline Ref. beam & GB & $\begin{array}{ll}----- \\
\end{array}$ & ----- & ----- & ----- & ----- \\
\hline \multirow{3}{*}{$\mathbf{A}$} & GT6 & Trapezoidal & 6 & 200 & 100 & 100 \\
\hline & GT8 & Trapezoidal & 8 & 150 & 100 & 100 \\
\hline & GT10 & Trapezoidal & 10 & 100 & 100 & 100 \\
\hline \multirow{3}{*}{ B } & GTH6 & Trapezoidal & 6 & 200 & 75 & 75 \\
\hline & GTH8 & Trapezoidal & 8 & 150 & 75 & 75 \\
\hline & GTH10 & Trapezoidal & 10 & 100 & 75 & 75 \\
\hline \multirow{3}{*}{$\mathbf{C}$} & GP6 & Trapezoidal with inclined posts & 6 & 200 & 100 & 100 \\
\hline & GP8 & Trapezoidal with inclined posts & 8 & 150 & 100 & 100 \\
\hline & GP10 & Trapezoidal with inclined posts & 10 & 100 & 100 & 100 \\
\hline \multirow{3}{*}{ D } & GC1 & Circular & 8 & $\mathrm{D}$ & 75 & 75 \\
\hline & GC2 & Circular & 8 & $0.83 \mathrm{D}$ & 100 & 100 \\
\hline & GC3 & Circular & 8 & $0.67 \mathrm{D}$ & 120 & 120 \\
\hline
\end{tabular}

Since many approximations are involved in modeling reinforced concrete for the calculation of deflection, accuracy within $\pm 20 \%$ usually is considered satisfactory for all design purposes. The predicted value of the maximum deflections at the assumed service load calculated by both the equation method from (1) and Direct Stiffness Method from (4) are presented together with the corresponding experimental values in Table II and Figure 8. In equations method the ratios of experimental to predicted deflections for beams with quadratic openings (nine beams) range from 1.04 to 1.21 , with an average of 1.15 and a coefficient of variation of $5 \%$, while the beams with circular openings (three beams) have ratios of experimental to predicted deflections ranging from 1.1 to 1.18 with an average of 1.14 and a coefficient of variation of $3.32 \%$. 
Note that for the total of 12 beams only one beam violated the acceptable accuracy of $\pm 20 \%$ by a negligible margin. In Direct Stiffness Method, the ratios of experimental to predicted deflections for beams with quadratic openings (nine beams) range from 0.95 to 1.15 , with an average of 1.07 and a coefficient of variation of $6.21 \%$, while the beams with circular openings (three beams) have ratios of experimental to predicted deflections ranging from 0.99 to 1.12 with an average of 1.06 and a coefficient of variation of $6 \%$. All 12 beams were within the acceptable accuracy of $\pm 20 \%$.

TABLE II. COMPARISON BETWEEN PREDICTED AND EXPERIMENTAL DEFLECTIONS AT CALCULATED SERVICE LOADS

\begin{tabular}{|c|c|c|c|c|c|c|c|c|c|c|c|}
\hline \multirow[b]{2}{*}{$\begin{array}{l}\text { Beam } \\
\text { Mark }\end{array}$} & \multirow[b]{2}{*}{ Load (kN) } & \multicolumn{5}{|c|}{ Deflection calculated by equation method } & \multicolumn{5}{|c|}{ Deflection calculated by Direct Stiffness Method } \\
\hline & & $\delta_{p}(\mathbf{m m})$ & $\delta_{\mathrm{e}}(\mathrm{mm})$ & $\frac{\delta e}{\delta p}$ & Mean & C.O.V & $\delta_{p}(\mathbf{m m})$ & $\delta_{\mathrm{e}}(\mathrm{mm})$ & $\frac{\delta \mathrm{e}}{\delta \mathrm{p}}$ & Mean & C.O.V \\
\hline GB & 52.94 & 7.86 & 8.18 & 1.04 & ---- & --- & 7.81 & 8.18 & 1.05 & --- & --- \\
\hline GT6 & 45.76 & 7.52 & 9.11 & 1.21 & \multirow{9}{*}{1.15} & \multirow{9}{*}{5.00} & 8.61 & 9.11 & 1.06 & \multirow{9}{*}{1.07} & \multirow{9}{*}{6.21} \\
\hline GT8 & 47.17 & 7.52 & 9.02 & 1.20 & & & 7.88 & 9.02 & 1.14 & & \\
\hline GT10 & 48.24 & 7.44 & 8.78 & 1.18 & & & 7.65 & 8.78 & 1.15 & & \\
\hline GTH6 & 43.48 & 8.09 & 9.31 & 1.15 & & & 8.89 & 9.31 & 1.05 & & \\
\hline GTH8 & 45.19 & 7.87 & 9.11 & 1.16 & & & 8.56 & 9.11 & 1.06 & & \\
\hline GTH10 & 47.35 & 7.67 & 9.05 & 1.18 & & & 8.02 & 9.05 & 1.13 & & \\
\hline GP6 & 48.51 & 7.97 & 8.58 & 1.08 & & & 8.64 & 8.58 & 0.99 & & \\
\hline GP8 & 49.30 & 7.86 & 9.14 & 1.16 & & & 8.44 & 9.14 & 1.08 & & \\
\hline GP10 & 49.65 & 7.66 & 7.94 & 1.04 & & & 8.32 & 7.94 & 0.95 & & \\
\hline GC1 & 47.94 & 7.54 & 8.89 & 1.18 & \multirow{3}{*}{1.14} & \multirow{3}{*}{3.32} & 7.92 & 8.89 & 1.12 & \multirow{3}{*}{1.06} & \multirow{3}{*}{6} \\
\hline GC2 & 50.59 & 7.65 & 8.74 & 1.14 & & & 8.11 & 8.74 & 1.08 & & \\
\hline GC3 & 51.71 & 7.73 & 8.53 & 1.10 & & & 8.56 & 8.53 & 0.99 & & \\
\hline
\end{tabular}

Service load is taken as the experimental ultimate load $/ 17, \delta_{p}=$ predicted deflection in $\mathrm{mm}, \delta_{e}=$ experimental deflection in $\mathrm{mm}$, Mean $=$ average of $\delta e / \delta p$, C.O.V $=$ coefficient of variation of $\delta e / \delta p=\frac{\text { standard deviation }}{\text { Mean }} * 100$

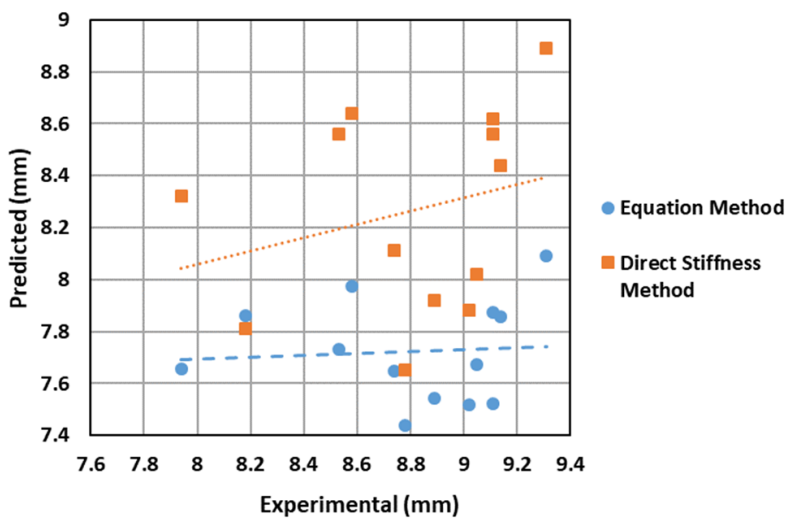

Fig. 8. Comparison of deflections at calculated service loads

\section{MAXIMUM CRACK WIDTH}

The flexural crack width at service stage can be calculated according to control requirements in ACI 318M-1995 code [5], using the following form:

$$
W_{\text {max }}=0.011 \beta f_{s} \sqrt[3]{d_{c} A_{O}} * 10^{-3} \mathrm{~mm}
$$

where $\beta=(h-x) /(d-x)$ is the ratio of the distance between the neutral axis and extreme tension face to the distance between the neutral axis and the centroid of reinforcing steel, $\beta=1.20$ in beams may be used to compare the crack widths obtained in flexure and axial tension, $f_{-} s=n *(M c) / I$ is the stress in the tension reinforcement calculated on the basis of a cracked section $\left(\mathrm{N} / \mathrm{mm}^{2}\right)$, $n=$ modular ratio $=E_{s} / E_{c}, d_{c}$ is the distance measured from the centroid of tensile steel to the extreme tensioned fiber, $A_{-} o=\left(2 d_{-} c b\right) / n_{-} b$ is the area of concrete surrounding each reinforcing bar, and $n_{b}$ is the number of tension reinforcing bars.
In the present study the width of flexural cracks is measured using a microscope during loading stages. Table III shows the maximum crack widths at the service loads, taken as the experimental ultimate loads divided by a load factor of 1.7. According to (6), the predicted maximum flexural crack width at service load for the reference beam (GB) is equal to $0.33 \mathrm{~mm}$, while the experimental value according to Table III is equal to $0.32 \mathrm{~mm}$ and the mean of the maximum crack width for the beams with openings is $0.36 \mathrm{~mm}$, so that it can be concluded that the insertion of opening in a solid beam increases the maximum flexural crack width by $12.5 \%$, therefore the equation of maximum crack width for beam with opening can be written as:

$$
W_{\max (\text { beam with opening })}=1.125 * W_{\max (\text { solid beam })}(\mathrm{mm})
$$

When using (7) to calculate the crack width of the tested beams under service loads as illustrated in Table III, it shows that for a total of 12 beams, the ratios of experimental to predicted maximum crack width range from 0.82 to 1.39 , with an average of 1.06 and a coefficient of variation of $15.6 \%$. Only two beams violated the acceptable accuracy of $\pm 20 \%$ (beam GTH6 and GTH8), where the maximum crack width for these two beams already marginally exceeded $0.4 \mathrm{~mm}$ (max. crack width $=0.43 \mathrm{~mm}$ for beam GTH6 and $0.41 \mathrm{~mm}$ for beam GTH8). The reason for this may be the reduction in depth of the upper and lower chords. On average, the proposed formula gives conservative predictions of maximum flexural crack width for beams with openings at service load. It is obvious from Table III that the provision of opening increases the maximum flexural crack width at service stage, in addition the increasing size of opening increases the maximum crack width at all load levels. Despite that the serviceability criterion of maximum crack width is satisfied by all beams, except for beams GTH6 and GTH8 as mentioned above. 
TABLE III. MAXIMUM CRACK WIDTH UNDER SERVICE LOAD

\begin{tabular}{|c|c|c|c|c|c|c|c|}
\hline Group & Beam Mark & Calculated services load $(\mathrm{kN})$ & $W_{e}(\mathbf{m m})$ & $W_{p}(\mathbf{m m})$ & $\frac{W e}{W p}$ & Mean & C.O.V \\
\hline Ref. beam & GB & 52.94 & 0.32 & $0.33^{*}$ & 0.97 & ---- & --- \\
\hline \multirow{3}{*}{ A } & GT6 & 45.76 & 0.39 & 0.33 & 1.18 & \multirow{12}{*}{1.06} & \multirow{12}{*}{15.6} \\
\hline & GT8 & 47.17 & 0.37 & 0.33 & 1.12 & & \\
\hline & GT10 & 48.24 & 0.33 & 0.34 & 0.97 & & \\
\hline \multirow{3}{*}{ B } & GTH6 & 43.48 & 0.43 & 0.31 & 1.39 & & \\
\hline & GTH8 & 45.19 & 0.41 & 0.32 & 1.28 & & \\
\hline & GTH10 & 47.35 & 0.35 & 0.34 & 1.03 & & \\
\hline \multirow{3}{*}{$\mathrm{C}$} & GP6 & 48.51 & 0.33 & 0.34 & 0.97 & & \\
\hline & GP8 & 49.30 & 0.32 & 0.35 & 0.91 & & \\
\hline & GP10 & 49.65 & 0.29 & 0.35 & 0.82 & & \\
\hline \multirow{3}{*}{ D } & $\mathrm{GC1}$ & 47.94 & 0.37 & 0.34 & 1.09 & & \\
\hline & GC2 & 50.59 & 0.35 & 0.35 & 1 & & \\
\hline & GC3 & 51.71 & 0.34 & 0.37 & 0.92 & & \\
\hline
\end{tabular}

\section{CONCLUSION}

For the calculation of deflection and crack width of reinforced concrete gable beams, two methods have been developed, the first method uses a general cumulative equation and the second is the Direct Stiffness Method. The Direct Stiffness Method is long and needs careful calculations for the flexural stiffness based on the cracked transformed section for each section. For crack width calculation, the equation of ACI $318 \mathrm{M}-1995$ code was used with magnification factor equal to 1.125 to predict crack width for beams with openings. The analytical results were compared with the experimental ones and on average the suggested methods to determine deflection and crack width for gable beams with openings at service loads give good predictions and satisfy design requirements.

\section{REFERENCES}

[1] S. P. Timoshenko, D. H. Young, Theory of Structures, McGraw-Hill, 1965

[2] G. B. Barney, W. G. Corley, J. M. Hanson, R. A. Parmelee, "Behavior and design of prestressed concrete beams with large web openings", PCI Journal, Vol. 22, No. 6, pp. 1977

[3] M. A. Mansur, L. M. Huang, K. H. Tan, S. L. Lee, "Deflections of Reinforced Concrete Beams with Web Openings", ACI Structural Journal, V. 89, No. 4, 1992

[4] N. J. Carino, J. R. Clifton, Prediction of Cracking in Reinforced Concrete Structures, Building and Fire Research Laboratory, National Institute of Standards and Technology, 1995

[5] ACI Standard: Commentary on Building Code Requirements for Structural Concrete (ACI 318R-95), 1995

[6] J. V. Amiri, M. H. ALibygie, "Effect of Small Circular Opening on the Shear and Flexural Behavior and Ultimate Strength of Reinforced Concrete Beams Using Normal and High Strength Concrete", 13th World Conference on Earthquake Engineering, Vancouver, Canada, August 1-6, 2004

[7] A. S. Al-Shaarbaf, N. A-M. J. Al-Bayati, D. I. A. Al-Kaisy, "Nonlinear Finite Element Analysis of Reinforced Concrete Beams with Large Opening under Flexure", Engineering \& Technology, Vol. 25, No. 2, pp. 210-228, 2007

[8] N. K. Oukaili, A. H. Shammari, "Response of Reinforced Concrete Beams with Multiple Web Openings to Static Load", Fourth AsiaPacific Conference on FRP in Structures, Melbourne, Australia, December 11-13, 2013

[9] B. Aykac, I. Kalkan, S. Aykac, Y. E. Egriboz, "Flexural behavior of RC beams with regular square or circular web openings", Engineering Structures, Vol. 56, pp. 2165-2174, 2013
[10] S. A. Al-Sheikh, "Flexural Behavior of RC Beams with Opening", Concrete Research Letters, Vol. 5, No. 2, pp. 812-824, 2014

[11] M. B. Dawood, R. A. A. Nabbat, "Flexural and Shear Strength of NonPrismatic Reinforced High Strength Concrete Beams with Openings and Strengthened WITH NSM-cfpr bars", International Journal of Civil Engineering and Technology, Vol. 6, No. 9, pp. 93-103, 2015

[12] K. H. Tan, Ultimate Strength of Reinforced Concrete Beams with Rectangular Openings Under Bending and Shear, MSc Thesis, National University of Singapore, 1982

[13] M. A. Mansur, K. H. Tan, Concrete Beams with Openings: Analysis and Design, CRC Press, 1999 